\title{
An, open Exploring differences in patient mix in
a cohort of GP trainees and their trainers
}

\author{
Jip De Jong, Mechteld R M Visser, Margreet Wieringa-de Waard
}

To cite: De Jong J, Visser MRM, Wieringa-de Waard M. Exploring differences in patient mix in a cohort of GP trainees and their trainers. BMJ Open 2011;1:e000318. doi:10.1136/

bmjopen-2011-000318

- Prepublication history and additional appendices for this paper are available online. To view these files please visit the journal online (http:// bmjopen.bmj.com).

Received 17 August 2011 Accepted 5 October 2011

This final article is available for use under the terms of the Creative Commons Attribution Non-Commercial 2.0 Licence; see http://bmjopen.bmj.com

Division of Clinical Methods and Public Health, Department of General Practice, Academic Medical Center, University of Amsterdam, Amsterdam, The Netherlands

Correspondence to Jip de Jong; jipdejong@amc.uva.nl

\section{ABSTRACT}

Background: During specialty training for general practice, trainees acquire the required competencies through work-based learning. Previous small-scale and older studies suggest that the patient mix of general practitioner (GP) trainees differs from that of their trainers: trainees are exposed to more minor illnesses, and fewer chronic diseases and severe conditions, which may influence the development of their competency.

Research question: What are the differences in the patient mix between trainees and trainers?

Methods: 49 first- and 24 third-year trainees and their trainers $(n=114)$ were included in the study.

International Classification of Primary Care (ICPC) contact and diagnosis codes were extracted from electronic patient records over 6 months.

Results: Trainers had double the number of face-toface consultations, and treble the number of telephone consultations compared with trainees. The trainees' patient mix consisted of significantly more patients with eye diseases, ear diseases, respiratory diseases, skin diseases and minor illnesses compared with their trainers. Trainers encountered significantly more patients with circulatory diseases, psychiatric diseases, metabolic diseases, male genital conditions, social problems, and chronic and oncological diseases. Female trainers and trainees encountered almost twice the number of female conditions compared with their male counterparts, while for male conditions, the opposite was found.

Discussion: Considerable differences between the patient mix of trainers and trainees were found. Specialty trainers and teachers must be aware of areas of low exposure. Trainers should ensure trainees handle more chronic, complex, psychosocial and circulatory conditions.

\section{INTRODUCTION}

During their specialty training, general practitioner (GP) trainees develop the required competencies through work-based learning involving clinical exposure to an adequate patient mix. The importance of an adequate patient mix was recently confirmed $^{1-3}$ and recognised by several national $^{4-6}$ and international ${ }^{7}$ accreditation

\section{ARTICLE SUMMARY}

Article focus

- Differences in patient mix between trainees and trainers were examined.

Key messages

- There are considerable differences between the patient mixes of trainers and trainees.

- Trainers and teachers must be aware of these disparities and of areas of low exposure.

- Trainers should ensure that trainees handle more chronic, complex, psychosocial and circulatory conditions.

Strengths and limitations of this study

- The patient mix during specialty training for general practice was studied on a large scale and over a long period.

- Information on patient mix extracted from electronic patient records system is excellent for monitoring patient mix.

- The validity of the study is potentially diminished by dependence on the diagnostic competence of the doctors and the accurate attribution of diagnosis codes.

standards. The World Federation for Medical Education emphasised in its Global Standards for Quality Improvement for Postgraduate Education $^{7}$ the importance of a broad range of experience in the trainee's chosen medical field.

But what is an adequate patient mix? The learning curve of individual trainees may vary, ${ }^{8} 9$ and successful work-based learning depends on many factors, such as learning style, ${ }^{10}$ independence ${ }^{3}$ and, especially, supervision. $^{3}{ }^{11}$ An adequate patient mix should contain enough diverse learning experiences $^{12}$ and should resemble the patient mix the trainees will be confronted with later as licensed GPs. ${ }^{13-15}$ To address this requirement and to determine lowexposure areas, the patient mix of trainees and their trainers should be analysed. Previous reports ${ }^{14-29}$ found that the trainees' patient mix consisted of more minor illnesses and fewer psychosocial, chronic and severe conditions compared with their trainers, 
demonstrating low exposure to important health conditions. ${ }^{30}$ These studies, however, are relatively old, ${ }^{14} 1621-2629$ were small scale $(n=8)^{20}$ or even case studies $(n=1),{ }^{14} 2123262829$ and often covered short periods ( $\leq 4$ weeks). ${ }^{15} 182224$ A larger study over a longer period has not been carried out recently.

Trainer insight into trainee patient mix should be encouraged and trainers should aim at a tailored mix to ensure adequate learning experiences. ${ }^{21}$ Tailoring could be achieved, for instance, by instructing the medical receptionist to request patients belonging to specific patient groups to attend the trainee. ${ }^{1321} 31$

If the patient mix is deficient due to unavoidable factors (eg, geographical location), a placement in a practice with a complementary patient mix could be arranged by the training institute. A detailed description of the patient mix can be established using logbooks 3233 or extracting data from electronic patient records (EPR), as in the present study. ${ }^{20} 3435$ Because proper medical reporting is considered of paramount importance, EPR systems are valid and reliable, and, unlike logbooks, do not require additional actions. The aim of this study was to investigate the differences in patient mix between GP trainees and their trainers.

\section{METHODS}

Participants and study setting

The study was conducted between 2008 and 2009 in practices affiliated to the GP specialty training programme of the Academic Medical Center, University of Amsterdam. This training institute facilitates a 3-year course in which first- and third-year trainees work in GPtraining practices. Trainees are assigned clinical rotations in their second year. Trainees work for $36 \mathrm{~h}$ per week, $29.5 \mathrm{~h}$ of which are spent in direct patient care. The average GP in the Netherlands worked for $44 \mathrm{~h}$ per week in $2001 .^{36}$

\section{Design and procedures}

Training practices about to accommodate a new trainee were identified. If trainers agreed to participate, their trainees were also approached for inclusion.

All participants gave informed consent. In the Netherlands, most GPs keep detailed EPRs utilising a standardised system of diagnosis codes set out in the International Classification of Primary Care (ICPC). The ICPC consists of 17 chapters covering the organ systems, a general chapter and a social chapter.

All participants received a visual aid describing the basic ICPC coding rules and some standard problems and solutions. All trainees attended a short session, in which the study was presented and the visual aid was explained. The trainers were instructed individually. GPs not certified as trainers who worked in training practices were included if they supervised the trainee for 1 day/ week or more.

Data were extracted over 6 months. Ethics approval was obtained from the Ethical Review Board of the Netherlands Association for Medical Education (NERB-ID 42).

\section{Data extraction}

We developed software to extract data from the EPR systems. ${ }^{37}$ The data contained aggregated information about ICPC diagnosis codes including information about the frequency of patient contacts by age group and consultation-type code. The chance of missing a consultation-type code was small since these are used for invoicing. Most EPR systems demand a consultation-type code for each contact with a patient and check for missing codes. The coding percentage was therefore always $100 \%$. Consultation-type codes determined whether the ICPC diagnosis codes were counted or not. Administration acts or repeat prescriptions were disregarded. The consultation-type codes were translated into three basic contact codes: telephone consultations, face-to-face consultations or home visits. Entering an ICPC diagnosis code in the EPR after seeing a patient is usually not mandatory, so the ICPC diagnosis coding percentage could be below $100 \%$.

\section{Statistical analyses}

Trainer-trainee differences were tested using ANOVA in SPSS V.18.0. The data of part-time workers were corrected to reflect full-time work. For the patient mix description, we used the mean percentages of the ICPC codes. To calculate these, the non-coded contacts were disregarded for each subject, and the total of the remaining codes was set to $100 \%$.

The coding percentages were calculated by dividing the total number of ICPC diagnosis codes in a trimester by that same number plus the number of non-coded contacts, corrected by the individual mean number of ICPC diagnosis codes per contact. If the coding percentage was below $50 \%$, the subject was excluded from the ICPC code analyses. We analysed several specific diseases and diseases clusters of interest for training purposes. To evaluate the number of chronic and oncological diseases encountered, we used the clusters published by Knottnerus et $a l^{38}$ For the description of minor illnesses and acute diseases, we asked five experienced GPs to score the appropriateness of (preselected) ICPC codes for these disease categories on a scale of 1-9. The ICPC code was included if the median score was higher than 7 and none of the scores was below 3 (see supplementary appendices 1 and 2). ${ }^{39}$

To ensure all learning experiences were represented, every ICPC diagnosis code entered during a patient contact was counted and we compared our data with those of the Netherlands Information Network of General Practice (LINH, 2009). ${ }^{40}$ These latter data were collected from a representative network of 84 general practices throughout the Netherlands, with about 140 GPs. ${ }^{40}$ The majority were not training practices. There were two differences compared with our data sampling: LINH data are primarily morbidity figures and based on the last ICPC code in a series of contacts (episodes); and the contacts of the medical receptionists and nurse practitioners (NPs) are included in the LINH data. We therefore also compared our results with older data, those of the second Dutch National Survey of General 
Practice (104 practices) which was carried out in 2001 (DNSGP-2, 2004).$^{41}$ The advantage of this comparison is that in 2001 only a few NPs were working in GP practices. The DNSGP-2 also used the LINH registration network.

\section{RESULTS}

\section{Participants}

Ninety-eight GP-training practices were approached and 73 were included in the study. ${ }^{37}$ Reasons for non-inclusion $(n=25)$ were: not used to diagnosis coding $(n=2)$, a recent/imminent change to a different (unsuitable) EPR $(n=5)$, illness $(n=2)$, no trainee assigned $(n=2)$ and refusal $(n=14)$.

A total of 49 first-year trainees and 24 third-year trainees were working in these 73 practices. There were 10 single, 17 dual and 46 group practices. There was one trainer in 32 of the training practices, and there were two or more in the remaining 41 . The data of 73 trainees and 114 trainers (102 officially certified and 12 supervising) were extracted. The trainees' mean age was 31.2 (SD 3.24) years and the trainers' mean age was 50.9 (SD 7.0) years; more than half of the trainers worked full-time $(n=59)$.

\section{Coding percentages of ICPC contact codes}

The mean percentage of the contacts containing at least one ICPC diagnosis code was $86.2 \%$ (SD 13.2, range $27.4 \%-100 \%$ ) for trainees and $78.9 \%$ (SD 22.4, range $2.3 \%-100 \%)$ for trainers. Forty-two trainees and 53 trainers had a coding percentage over $90 \%$. Fourteen trainers and two trainees had a mean ICPC coding percentage below $50 \%$ and their ICPC diagnosis code data were disregarded. Of the remaining participants, the mean coding percentage was $88.1 \%$ (SD 9.7) for trainees and $85.6 \%$ (SD 12.7) for trainers.

\section{Consultations and home visits}

The mean number of trainee consultations per trimester was 461.2 (SD 115.6) for face-to-face contact, 67.7 (SD 43.7) for telephone contact and 35.6 (SD 28.9) for home visits.

Trainers averaged 975.7 (SD 224.9) face-to-face consultations, 215.7 (SD 129.1) telephone consultations and 68.0 (SD 46.9) home visits per trimester.

\section{Distribution of patients' ages}

Data from face-to-face consultations, telephone consultations and home visits were combined to determine patients' ages (figure 1). Univariate analysis showed significant differences in all age groups $(p \leq 0.00)$ between trainers and trainees, except for the 25-44 and $75+$ year old patient groups.

\section{Organ systems (ICPC chapters)}

In figure 2, the results for all participants are combined. The DNSGP-2 data seem to be similar to our results, except for female conditions (pregnancy and female genital). The LINH 2009 figures differ on circulatory and metabolic/endocrinology, the areas in which most NPs are active.

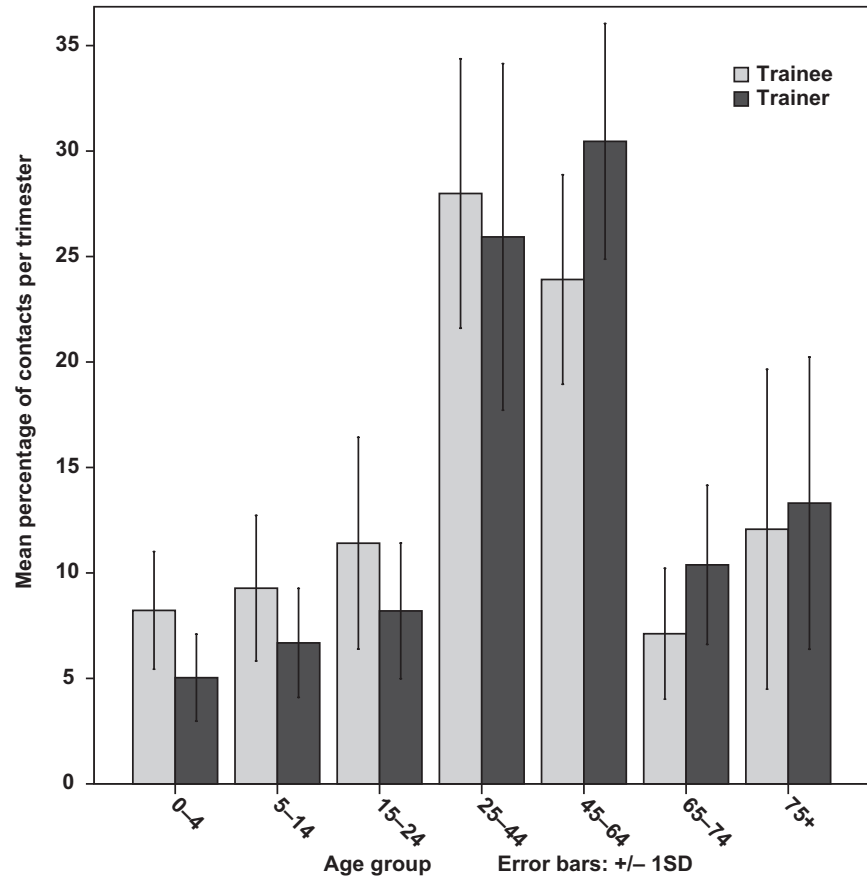

Figure 1 Proportions (\%) of contacts of trainees $(n=73)$ and trainers $(n=105)$, displayed per age group. The data of nine trainers had to be disregarded; their data were biased by large numbers of influenza vaccinations that could not be traced back to the proper age group.

\section{Most common ICPC diagnoses}

Acute respiratory infections headed the trainees' top- 10 list (table 1), and when they were combined with cough, sinusitis and bronchitis, and compared with the trainers' data, the differences for upper respiratory tract infections were even more apparent. Otitis media was ranked 7 th for trainees, compared with 25th $(0.71 \%)$ for trainers. Hypertension topped the trainers' list. Diabetes mellitus and depression were in the trainers', but not in the trainees', top 10 (nos. $21(0.97 \%)$ and $40(0.85 \%)$, respectively).

Proportions of patient mix for specific diseases and disease clusters

Female doctors (trainees and trainers combined) saw more female conditions $(\mathrm{p}<0.001)$ than their male colleagues. Female trainees saw an average percentage of $6.6 \%$ female conditions as opposed to $3.9 \%$ for male trainees. For female trainers this percentage was $8.1 \%$ versus $4.8 \%$ for male trainers. Male doctors saw more male conditions $(p=0.001)$ than their female colleagues. Male trainees saw an average percentage of $1.3 \%$ male conditions and female trainees saw $1.1 \%$; for male trainers this was $1.9 \%$ versus $1.3 \%$ for female trainers. For more disease clusters see table 2.

\section{DISCUSSION}

Seventy-three GP-training practices were investigated. Trainees saw a higher percentage of young patients, but fewer cardiovascular risk management (CVRM)primary prevention, chronic and oncological conditions, 
Figure 2 Mean percentages and SD (error bars) of ICPC diagnoses codes, aggregated by chapter for trainers $\left(n=100^{\star}\right)$ and for trainees $\left(n=71^{\star}\right)$ and reference data of DNSGP-2** and LINH 2009**. *The data of 14 trainers and two trainees were disregarded because their mean ICPC coding percentage was lower than $50 \%$. ${ }^{\star \star}$ The Dutch National Survey of General Practice (DNSGP-2) and Netherlands Information Network of General Practice (LINH 2009) are based on prevalences per 1000 patients.DNSGP-2, Dutch National Survey of General Practice, 2004; ICPC, International Classification of Primary Care; LINH, Netherlands Information Network of General Practice.

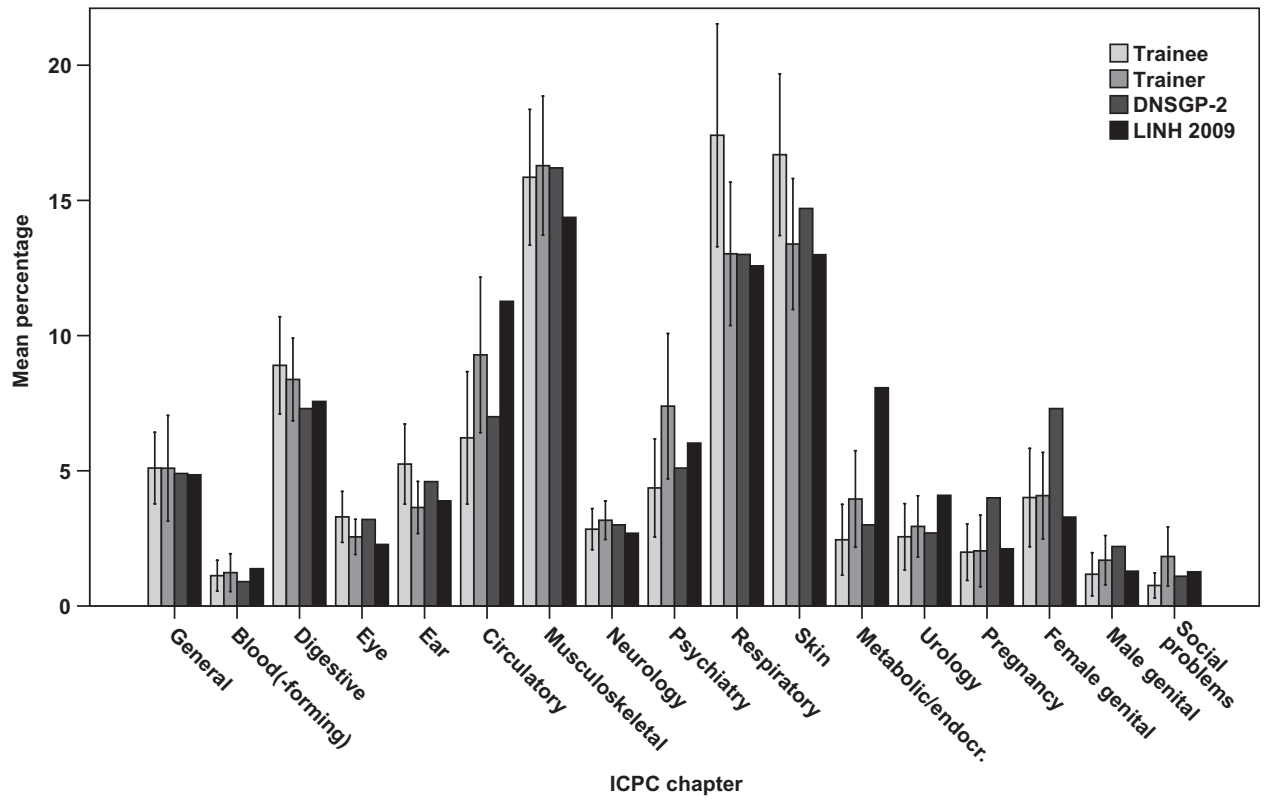

Error bars $+/-1 \mathrm{SD}$ and fewer circulatory and psychiatric diseases, social problems and neurological conditions (third year only) than their trainers. They saw more skin, ear and respiratory diseases and minor illnesses. In the first training year, they saw noticeably fewer acute diseases, and male genital and metabolic diseases (specifically diabetes and CVRM-secondary prevention), but more eye diseases.

Similar to other studies addressing trainee patient mix, ${ }^{15} 18{ }^{20}$ trainees saw more minor illnesses than their trainers. This is notable but not necessarily worrisome. Boredom and 'saturation' could be a concern, but are unlikely since the social background of the patients usually offers sufficient challenges for the trainees. For instance, by seeing children together with their parent(s) a trainee becomes familiar with the role of the family doctor. In addition, the most frequently encountered disease (acute respiratory infection) constituted only $5.2 \%$ of the trainees' patient mix (table 1 ).

As in other studies, ${ }^{15} 1820$ trainees saw fewer chronic and oncological ${ }^{15}$ conditions. This is interesting, since Darer $^{30}$ found that the majority of US GPs felt inade- quately trained for chronic diseases, and Card ${ }^{42}$ reported that recently graduated internists felt insufficiently prepared for chronic care. As previously reported, 20 23242643 the trainees saw fewer psychosocial conditions. Given these findings and the multimorbidity of the ageing population, ${ }^{44}$ we believe that trainees should handle more severe, chronic and complex patients, and an intervention to shift the patient mix towards the level of the trainer is worth considering.

Eccles, ${ }^{18}$ Fleming $^{24}$ and others ${ }^{14} 232628$ found that male and female trainees saw fewer female conditions than their trainers. Our results show that the differences regarding female conditions were due to the doctors' gender only, as also found by Levy in a 3-week family medicine preceptorship. ${ }^{45}$ This might have implications for the competence building of male trainees.

Differences found in previous studies regarding circulatory, 14202123242628 metabolic, ${ }^{20} 232426$ skin,, 2021232426 eye, ${ }^{20}{ }^{26}$ ear $^{26}$ (in most studies, the sense organs were combined with the nervous system) and respiratory diseases 1421232426 were confirmed in our study.

\begin{tabular}{|c|c|c|c|c|}
\hline Ranking & Trainee $(\mathrm{N}=71)$ & $\%$ & Trainer $(\mathrm{N}=100)$ & $\%$ \\
\hline 1 & Acute respiratory infection & 5.2 & Hypertension & 4.5 \\
\hline 2 & Cough & 2.7 & Acute respiratory infection & 2.5 \\
\hline 3 & Hypertension & 2.3 & Diabetes mellitus & 1.8 \\
\hline 4 & Dermatomycosis & 1.8 & Cough & 1.8 \\
\hline 5 & Low-back pain & 1.4 & Low-back pain & 1.5 \\
\hline 6 & Cystitis or other urinary infection & 1.4 & Depression & 1.5 \\
\hline 7 & Otitis media & 1.4 & Cystitis or other urinary infection & 1.4 \\
\hline 8 & Acute or chronic sinusitis & 1.4 & Weakness/tiredness & 1.4 \\
\hline 9 & Weakness/tiredness & 1.3 & Dermatomycosis & 1.3 \\
\hline 10 & Acute bronchitis/bronchiolitis & 1.3 & Asthma & 1.3 \\
\hline
\end{tabular}


Table 2 Comparisons of the patient mixes of trainees and trainers for specific diseases and disease clusters between the first and third training year

\begin{tabular}{|c|c|c|c|c|}
\hline $\begin{array}{l}\text { ICPC chapter/ } \\
\text { cluster/disease }\end{array}$ & $\begin{array}{l}\text { First-year trainees } \\
(\mathrm{N}=48) \text {, mean \% } \\
(\mathrm{SD})\end{array}$ & $\begin{array}{l}\text { First-year trainers } \\
(\mathrm{N}=64) \text {, mean \% } \\
(\mathrm{SD})\end{array}$ & $\begin{array}{l}\text { Third-year trainees } \\
(\mathrm{N}=23) \text {, mean } \% \\
(\mathrm{SD})\end{array}$ & $\begin{array}{l}\text { Third-year trainers } \\
(\mathrm{N}=36) \text {, mean } \% \\
(\mathrm{SD})\end{array}$ \\
\hline \multicolumn{5}{|l|}{ ICPC chapters } \\
\hline General & $5.1(1.5)$ & $5.1(1.5)$ & $5.1(2.1)$ & $5.1(2.3)$ \\
\hline Blood (-forming) & $0.9(0.5)$ & $1.2(0.5)$ & $1.3(0.6)$ & $1.3(0.9)$ \\
\hline Digestive & $8.9(1 / 7)$ & 8.5 (1.3) & $8.9(1.9)$ & $8.3(1.7)$ \\
\hline Eye & $3.3(0.8)$ & $2.4(0.6) \dagger$ & $3.3(1.1)$ & $2.7(0.7)$ \\
\hline Ear & $5.7(1.6)$ & $3.8(1.0) \dagger$ & 4.8 (1.3) & $3.5(0.9) \dagger$ \\
\hline Circulatory & $5.6(2.6)$ & $9.0(3.3) \dagger$ & $6.8(2.1)$ & $9.5(2.4) \dagger$ \\
\hline Musculoskeletal & $16.4(2.7)$ & $16.4(2.7)$ & $15.3(2.2)$ & $16.2(2.5)$ \\
\hline Neurology & $3.0(0.8)$ & $3.1(0.8)$ & $2.7(0.7)$ & $3.2(0.7)^{\star}$ \\
\hline Psychiatry & $3.7(1.7)$ & $7.0(2.0) \dagger$ & $5.0(1.8)$ & $7.8(3.2) \dagger$ \\
\hline Respiratory & $18.3(3.5)$ & $13.8(2.4) \dagger$ & $16.5(4.6)$ & $12.3(2.7) \dagger$ \\
\hline Skin & $16.7(3.1)$ & $12.9(2.0) \dagger$ & $16.7(2.9)$ & $13.8(2.8) \dagger$ \\
\hline Metabolic/endocrine & $2.1(1.1)$ & $4.1(1.8) \dagger$ & $2.8(1.4)$ & $3.8(1.8)$ \\
\hline Urology & $2.4(1.0)$ & $2.9(1.0)$ & $2.7(1.5)$ & $3.0(1.2)$ \\
\hline Pregnancy & $2.0(1.2)$ & $2.3(1.6)$ & $2.0(0.9)$ & $1.7(0.9)$ \\
\hline Female genital & $3.9(2.3)$ & $4.3(1.8)$ & $4.1(1.2)$ & $3.9(1.4)$ \\
\hline Male genital & $1.1(0.5)$ & $1.5(0.6) \dagger$ & $1.2(1.0)$ & $1.9(1.1)$ \\
\hline Social problems & $0.8(0.5)$ & $1.7(1.1) \dagger$ & $0.8(0.4)$ & $1.9(1.1) \dagger$ \\
\hline \multicolumn{5}{|l|}{ Cluster } \\
\hline Acute diseases $\ddagger$ & $1.8(0.7)$ & $2.3(0.8) \dagger$ & $2.2(0.9)$ & $2.4(0.8)$ \\
\hline Chronic diseases & $8.7(3.2)$ & $15.8(5.3) \dagger$ & $10.8(3.4)$ & $16.2(4.6) \dagger$ \\
\hline Oncological & $0.4(0.4)$ & $1.7(1.4) \dagger$ & $0.9(0.9)$ & $1.8(1.4)^{\star}$ \\
\hline Diabetes mellitus & $0.8(0.8)$ & $1.9(1.3) \dagger$ & $1.2(1.3)$ & $1.7(1.4)$ \\
\hline $\begin{array}{l}\text { CVRM-primary§ } \\
\text { (not diabetes) }\end{array}$ & $2.8(1.7)$ & $5.8(2.4) \dagger$ & $3.7(1.5)$ & $6.2(2.2) \dagger$ \\
\hline CVRM-secondary & $0.3(0.2)$ & $0.7(0.5) \dagger$ & $0.4(0.5)$ & $0.8(0.5)$ \\
\hline COPD & $0.60(0.6)$ & $0.9(0.7)$ & $0.7(0.5)$ & $0.7(0.5)$ \\
\hline Minor illnessesł & $36.3(5.9)$ & $27.8(4.8) \dagger$ & $35.9(6.4)$ & $28.8(5.9) \dagger$ \\
\hline Symptom diagnosis & $46.2(6.9)$ & $40.4(6.8) \dagger$ & $43.1(7.5)$ & $39.9(6.8)$ \\
\hline \multicolumn{5}{|l|}{ Other diseases } \\
\hline Hypothyroiditis & $0.1(0.2)$ & $0.4(0.3) \dagger$ & $0.2(0.3)$ & $0.4(0.3)$ \\
\hline Asthma & $1.1(0.7)$ & $1.3(0.6)$ & $1.1(0.6)$ & $1.3(0.7)$ \\
\hline $\begin{array}{l}\text { Depression or depressed } \\
\text { feelings }\end{array}$ & $0.8(0.6)$ & $1.8(0.8) \dagger$ & $1.0(0.8)$ & $1.8(1.1)^{*}$ \\
\hline Irritable bowel syndrome & $0.3(0.3)$ & $0.5(0.4)^{\star}$ & $0.4(0.4)$ & $0.5(0.4)$ \\
\hline Conjunctivitis & $0.7(0.5)$ & $0.4(0.2) \dagger$ & $0.9(0.6)$ & $0.5(0.3) \dagger$ \\
\hline Sore throat ${ }^{\star \star}$ & $1.7(0.8)$ & $1.0(0.5) \dagger$ & $1.6(0.7)$ & $0.9(0.4) \dagger$ \\
\hline
\end{tabular}

${ }^{*}$ Differences between trainers and trainees, $p<0.01$. First- and third-year trainees were tested separately against their trainers.

$+\mathrm{p}<0.001$.

FThe ICPC codes of these clusters are listed in the supplementary appendices.

$\S$ Cardiovascular risk management, primary prevention: problems labelled as diagnostic, screening and preventive procedures of the

cardiovascular system, complicated or uncomplicated hypertension, atherosclerosis, tobacco abuse, obesity, overweight and lipid disorder. TCardiovascular risk management, secondary prevention: ischaemic heart disease (with or without angina), myocardial infarction, transient ischaemic attack, stroke, intermittent claudication and aortic aneurysm. This cluster was derived from the Advice on the Recording of CVRM of the Dutch College of General Practitioners (NHG).

${ }^{*}$ Sore throat, tonsillitis, pharyngitis and peritonsillar abscess.

COPD, chronic obstructive pulmonary disease; CVRM, cardiovascular risk management; ICPC, International Classification of Primary Care.

Generally, where a significant difference was found between the mean percentages of ICPC diagnosis codes encountered by the trainees and their trainers (figure 2), the DNSGP-2 percentages were between those of the trainers and those of the trainees. Therefore, the trainees' percentage was closer to that of the average GP than to that of the trainers. Apparently, patient supply is divided unequally, in the majority of the ICPC chapters. This uneven division was seen less often when compared to LINH 2009.
Most data were collected in the common-cold season, explaining the higher proportion of respiratory diseases. Trainees probably see most of the seasonal surplus because they usually treat patients on a shortterm basis.

Pregnancy tests, contraceptive injections and PAP smears carried out by medical receptionists were disregarded in our data, whereas the DNSGP-2 included these. This might explain the differences regarding female conditions. However, the LINH online figures for 
2002-2009 on female conditions were in the same range as our data. ${ }^{40}$

The fact that trainers saw more patients than trainees can be partly explained by their working hours. Closer examination showed that the trainees' workload increased over time.

Differences in patient mix may be caused by patients' preferences for a specific doctor. Patients do not always want to consult a trainee for various reasons, for instance chronic or emotional problems were found to be associated with reduced willingness to consult registrars. ${ }^{46}$ Also, in another study, medical receptionists reported that patients with complex conditions were relatively more often assigned to the trainer. ${ }^{31}$

Offering the trainees an adequate patient mix can be regarded as an educational obligation. ${ }^{45}$ Nevertheless, whether or not to assign patients with chronic or complex conditions to the trainee should be carefully weighed by trainers who can experience a conflict of interest since they are also responsible for the quality of healthcare provided. Dealing with this conflict is a professional challenge.

This study was unable to relate what the trainees saw to how much they learnt. Despite this, detailed knowledge of the trainees' patient mix has important educational implications when the curriculum is being planned. However, disparities in patient mix between trainers and trainees may not actually be problematic since several studies have shown that supervision is of crucial importance. ${ }^{11}$ In case of scarcity, it might be possible to build competence despite a lower level of exposure. Trainees and trainers should therefore be aware of areas of low exposure and disparity. Trainers could increase the number of patients seen by the trainees in these areas or provide special supervised sessions for low-exposure conditions. Trainees should build expert performance in the areas they will frequently encounter. For low-exposure areas, learning aims should be to achieve minimum competence, concentrating on initial treatment and not missing important diagnoses.

Data obtained from EPR can be used to identify features of training practices, such as the attendance of many elderly patients or young children. Thus, when trainees are being allocated, their learning objectives can be matched to the practice features.

\section{Limitations}

Since the patient supply in training practices is shared between trainer and trainee, the trainer's patient mix might vary from that normally encountered by an average GP. We therefore also compared our data with external data, which showed several apparent similarities, even though the data are not fully comparable.

The assumption that trainers or other GPs have an adequate patient mix is debatable. Alternatively, the trainees' patient mix can be compared to standards used in GP specialist training. ${ }^{20} 47$ These are consensus standards and largely based on national morbidity figures and therefore rest on the same assumption. From an educational perspective, these standards lack a scientific basis. More specific evidence is needed concerning the relationship between patient mix and learning so that patient mix can be optimised.

Trainers with a coding percentage over $90 \%$ saw more psychiatry and social problems than trainers in the $50 \%-90 \%$ range (not reported), indicating that psychosocial codes are under-reported by some trainers. This was not found for trainees.

Although ICPC coding is useful for describing patient mix, its validity is potentially diminished by its dependence on the diagnostic competence of doctors and the accurate attribution of codes (eg, definite instead of symptom diagnosis).

All participants were affiliated to one training institute. However, we do not think that this influenced the results, as other, different studies have shown similar results.

Minor illnesses and acute diseases were interesting as regards the description of learning experiences. Previous authors reporting on these clusters were implicit about their contents. ${ }^{15} 18 \quad 20$ We therefore created these clusters ourselves, but only with medium methodological rigour. Future studies should construct valid, sound thematic clusters which have educational meaning.

\section{CONCLUSION}

We studied the patient mix of GP-training practices using EPR on a large scale and over a long period and confirmed that the disparities between the patient mixes of trainers and trainees are considerable but stable over time and location. The difference in contact frequencies needs attention, as does exposure to chronic, psychosocial and circulatory diseases, and, probably, severe and complex conditions. Trainees should be given the opportunity to handle these conditions more frequently. Future studies should focus on interventions to tailor the patient mix, by, for instance, focussing on low-exposure areas. Individual trainee's patient mix should be adjusted to their personal development plan. EPR systems are excellent for permanently monitoring this patient mix, and thereby the trainee's learning experiences.

Funding This research received no specific grant from any funding agency in the public, commercial or not-for-profit sectors.

\section{Competing interests None.}

Ethics approval This study was approved retrospectively by the Ethical Review Board of the Netherlands Association for Medical Education (NERB-ID 42) in an online procedure. Please note that this review board was instituted on 16 July 2010. Before this date, educational research did not require ethics approval because according to Dutch law no approval was needed.

Contributors JdJ was the primary investigator, designed the study, acquired, analysed and interpreted the data, wrote the article and approved the final version to be published. MRMV designed and supervised the study, assisted in the acquisition and interpretation of data, revised the article critically for important intellectual content, and approved the final version to be published. MWdW designed and supervised the study, assisted in the analysis and 
interpretation of data, revised the article critically for important intellectual content, and approved the final version to be published.

Provenance and peer review Not commissioned; externally peer reviewed.

Data sharing statement No additional data available.

\section{REFERENCES}

1. Dolmans $\mathrm{DH}$, Wolfhagen IH, Essed GG, et al. The impacts of supervision, patient mix, and numbers of students on the effectiveness of clinical rotations. Acad Med 2002;77:332-5.

2. Dornan T, Bundy C. What can experience add to early medical education? Consensus survey. BMJ 2004;329:834

3. Van der Zwet J, Hanssen VG, Zwietering PJ, et al. Workplace learning in general practice: supervision, patient mix and independence emerge from the black box once again. Med Teach 2010:32:e294-9.

4. Functions and Structure of a Medical School. Standards for Accreditation of Medical Education Programs Leading to the M.D. Degree. Liaison Committee on Medical Education (LCME), 2011. II. B.1:p.8. http://www.lcme.org/functions2011may.pdf

5. Standards for GP Specialty Training: Guidance to Deaneries. Royal College of General Practitioners (RCGP), 2008. domain 5:p.7. http://www.rcgp-curriculum.org.uk/PDF/qmts_GP_Specific_Training Standards dec08.pdf

6. Accreditation of Specialist Medical Education and Training and Professional Development Programs: Standards and Procedures. Australian Medical Council Limited (AMC), 2011. p.6 note 2. http://www.amc.org.au/images/forms/Standards-for-specialistmedical-training-2011-Final.pdf

7. Karle H. Postgraduate Medical Education WFME Global Standards for Quality Improvement. Denmark: University of copenhagen, 2003:17. 6.1. http://www3.sund.ku.dk

8. Van Diest DR, Van Dalen J, Bak M, et al. Growth of knowledge in psychiatry and behavioural sciences in a problem-based learning curriculum. Med Educ 2004;38:1295-301.

9. Verhoeven BH, Verwijnen GM, Scherpbier AJ, et al. Growth of medical knowledge. Med Educ 2002;36:711-17.

10. Engels PT, De Gara C. Learning styles of medical students, general surgery residents, and general surgeons: implications for surgical education. BMC Med Educ 2010;10:51.

11. Wimmers PF, Schmidt HG, Splinter TA. Influence of clerkship experiences on clinical competence. Med Educ 2006;40:450-8.

12. Witzke DB, Koff NA, McGeagh AM, et al. Developing a computerbased system to document and report students' clinical patient encounters. Acad Med 1990;65:440-1.

13. Fouracre R, Savory JN. Steering patients with selected conditions to trainees. J R Coll Gen Pract 1980;30:729-33.

14. Stubbings $\mathrm{CA}$, Gowers $\mathrm{JI}$. A comparison of trainee and trainer clinical experience. J R Coll Gen Pract 1979;29:47-52.

15. Weeda G, Hutter AW, Groenier KH, et al. The workload of trainees in general practice. Med Educ 1997;31:138-43.

16. Wollstadt LJ. Case mix in a primary care teaching practice for two clerkship schedules. J Fam Pract 1979;8:107-12.

17. Tan LH. Tekorten in de huisartsopleiding. [Thesis]. Deficiencies in the Curriculum of the Vocational Training for General Practitioners. Amsterdam: University of Amsterdam, 1989.

18. Eccles M, Bamford C, Steen N, et al. Case mix and content of trainee consultations: findings from the north of England study of standards and performance in general practice. Br J Gen Pract 1994;44:437-40.

19. Markham FW, Rattner S, Hojat M, et al. Evaluations of medical students' clinical experiences in a family medicine clerkship: differences in patient encounters by disease severity in different clerkship sites. Fam Med 2002;34:451-4.

20. Vintges $M$, Van Weert $\mathrm{H}$, Wiele $\mathrm{E}$, et al. What health problems do trainees in general practice see? Data from electronic patient records compared with the 'Qualification terms' of the Dutch vocational training for general practitioners. Huisarts en Wetenschap 2001;44:485-9.

21. Adam J, Oswald N. What does a trainee see? J R Coll Gen Pract 1985;35:230-4.
22. Caine N, Strang J, Acheson RM. Study of trainer/trainee workload with special reference to the care of the elderly. $J R$ Coll Gen Pract 1985;35:419-22.

23. Carney TA. Clinical experience of a trainee in general practice. $J R$ Coll Gen Pract 1979;29:40-4.

24. Fleming DM. A comparison of the practice activities of trainees and principals. J R Coll Gen Pract 1986;36:212-16.

25. Parkerson GR Jr, Michener JL, Muhlbaier LH, et al. Clinical experience of medical students in model family practices and private family practices. J Fam Pract 1986;23:361-6.

26. Pearson CR, Goss BM. Comparison of the workload of a trainer and trainee. J R Coll Gen Pract 1989;39:320-3.

27. Snell LM, Battles JB, Bedford JA, et al. Verifying the curriculum of a family medicine clerkship. Med Educ 1998;32:370-5.

28. O'Flanagan PH. One trainee's clinical experience. J R Coll Gen Pract 1977;27:227-30.

29. Parkerson GR Jr, Griffin EW. Clinical experience during family medicine residency training. South Med J 1987;80:895-900.

30. Darer JD, Hwang W, Pham HH, et al. More training needed in chronic care: a survey of US physicians. Acad Med 2004:79:541-8.

31. De Jong J, Visser MR, Wieringa-de Waard M. Who determines the patient mix of GP trainees? The role of the receptionist. Fam Pract 2011:28:287-93.

32. Hilmy N. The project of updating and evaluating the Milton Keynes general practice vocational training scheme (MKVTS) logbook. Educ Prim Care 2007;18:757-8.

33. Raghoebar-Krieger HM, Sleijfer D, Bender W, et al. The reliability of logbook data of medical students: an estimation of interobserver agreement, sensitivity and specificity. Med Educ 2001;35:624-31.

34. Alderson TS, Oswald NT. Clinical experience of medical students in primary care: use of an electronic log in monitoring experience and in guiding education in the Cambridge Community Based Clinical Course. Med Educ 1999;33:429-33.

35. Nkoy FL, Petersen S, Antommaria AH, et al. Validation of an electronic system for recording medical student patient encounters. AMIA Annu Symp Proc 2008:510-14.

36. Van den Berg M. Workload in General Practice. NIVEL (Dutch Institute for Health Services Research), 2010. http://www.nivel.nl/pdf/ Proefschrift-Michael-van-den-Berg.pdf

37. De Jong J, Visser MRM, Mohrs J, et al. Opening the black box: The patient mix of GP trainees. Br J Gen Pract 2011;61:e650-e7.

38. Knottnerus JA, Metsemaker J, Höppener $P$, et al. Chronic Illness in the community and the concept of 'social prevalence'. Fam Pract 1992;9:15-21.

39. Campbell SM, Cantrill JA, Roberts D. Prescribing indicators for UK general practice: Delphi consultation study. BMJ 2000;321:425-8.

40. LINH (Netherlands Information Network of General Practice). 2009. http://www.linh.nl

41. Van der Linden M, Westert GP, Schellevis FG, et al. Tweede Nationale Studie: naar ziekten en verrichtingen in de huisartspraktijk. (Second National Study into Diseases and Actions in General Practice). Utrecht (Bilthoven): NIVEL (Dutch Institute for Health Services Research) and RIVM (National Institute of Public Health and Environment), 2004.

42. Card SE, Snell L, O'Brien B. Are Canadian General Internal Medicine training program graduates well prepared for their future careers? BMC Med Educ 2006;6:56.

43. St George IM. What do trainee interns see in general practice? $N Z$ Med J 1982:95:506-7.

44. Kadam UT, Croft PR; North Staffordshire GP Consortium Group. Clinical multimorbidity and physical function in older adults: a record and health status linkage study in general practice. Fam Pract 2007;24:412-19.

45. Levy BT, Merchant ML. Differences in clinical experiences based on gender of third-year medical students in a required family medicine preceptorship. Acad Med 2002;77:1241-6.

46. Bonney A, Phillipson L, Reis S, et al. Patients' attitudes to general practice registrars: a review of the literature. Educ Prim Care 2009;20:371-8.

47. Johnson N, Hasler J, Toby J, et al. Consensus minimum standards for use in a trainer's report for summative assessment in general practice. Br J Gen Pract 1996;46:140-4. 